Article

\title{
The Inhibitory Effect of Propylene Glycol Alginate Sodium Sulfate on Fibroblast Growth Factor 2-Mediated Angiogenesis and Invasion in Murine Melanoma B16-F10 Cells In Vitro
}

\author{
He Ma ${ }^{1}$, Peiju Qiu ${ }^{1,2,3,4, *}$, Huixin Xu ${ }^{1}$, Ximing Xu ${ }^{1,2,3,4}$, Meng Xin ${ }^{1,2,3,4}$, Yanyan Chu ${ }^{1,2,3,4}$, \\ Huashi Guan 1,2,3,4, Chunxia Li ${ }^{1,3}$ (D) and Jinbo Yang 1,2,3,4,* \\ 1 Key Laboratory of Marine Drugs of Ministry of Education, Shandong Provincial, \\ Key Laboratory of Glycoscience and Glycotechnology, School of Medicine and Pharmacy, \\ Ocean University of China, Qingdao 266003, China; mahe1992mahe@163.com (H.M.); \\ xvhuixin@hotmail.com (H.X.); xuximing@ouc.edu.cn (X.X.); xinmeng512@126.com (M.X.); \\ mary0312332@126.com (Y.C.); hsguan@ouc.edu.cn (H.G.); lchunxia@ouc.edu.cn (C.L.) \\ 2 Innovation Center for Marine Drug Screening \& Evaluation, Pilot National Laboratory for Marine Science \\ and Technology (Qingdao), Qingdao 266237, China \\ 3 Laboratory for Marine Drugs and Bioproducts of Pilot National Laboratory for Marine Science and \\ Technology (Qingdao), Qingdao 266237, China \\ 4 Marine Biomedical Research Institute of Qingdao, Qingdao 266071, China \\ * Correspondence: peijuqiu@ouc.edu.cn (P.Q.); yangjb@ouc.edu.cn (J.Y.); Tel.: +86-532-85906859 (P.Q.); \\ +86-532-82032030 (J.Y.)
}

Received: 5 March 2019; Accepted: 23 April 2019; Published: 29 April 2019

\begin{abstract}
Melanoma is one of the most malignant and aggressive types of cancer worldwide. Fibroblast growth factor 2 (FGF2) is one of the critical regulators of melanoma angiogenesis and metastasis; thus, it might be an effective anti-cancer strategy to explore FGF2-targeting drug candidates from existing drugs. In this study, we evaluate the effect of the marine drug propylene glycol alginate sodium sulfate (PSS) on FGF2-mediated angiogenesis and invasion. The data shows that FGF2 selectively bound to PSS with high affinity. PSS inhibited FGF2-mediated angiogenesis in a rat aortic ring model and suppressed FGF2-mediated invasion, but not the migration of murine melanoma B16-F10 cells. The further mechanism study indicates that PSS decreased the expression of activated matrix metalloproteinase 2 (MMP-2) and matrix metalloproteinase 9 (MMP-9), and also suppressed their activity. In addition, PSS was found to decrease the level of Vimentin in B16-F10 cells, which is known to participate in the epithelial-mesenchymal transition. Notably, PSS did not elicit any changes in cancer cell viability. Based on the results above, we conclude that PSS might be a potential drug to regulate the tumor microenvironment in order to facilitate the recovery of melanoma patients.
\end{abstract}

Keywords: propylene glycol alginate sodium sulfate; angiogenesis; invasion; FGF2; MMP-2; MMP-9

\section{Introduction}

Melanoma is one of the most malignant and aggressive types of cancer worldwide, and the identification of new targets for treating melanoma is urgently needed. Melanoma cells have been reported to constitutively express fibroblast growth factor 2 (FGF2) [1,2], which is an autocrine factor and promotes the proliferation, angiogenesis, and metastasis of melanoma cells. Thus, FGF2 is commonly considered one of the potential targets for treating melanoma, and may be used with other targets to synergistically enhance therapeutic efficacy [3]. 
FGF2, which belongs to the FGF family, participates in a variety of physiological and pathological processes both in vitro and in vivo, including cellular survival, differentiation, proliferation, angiogenesis, adhesion, skeletal formation, and wound healing [4-6]. In terms of function, FGF2 first binds to two fibroblast growth factor receptors (FGFRs), and then recruits the heparan sulfate (HS) chain(s) of membrane-anchored heparan sulfate proteoglycan (HSPGs) for assembly into a ternary complex (FGF-HS-FGFR). The FGF-HS-FGFR complex results in receptor dimerization, with subsequent autophosphorylation of specific tyrosine residues that affects multiple downstream signal transduction pathways [7-10]. Meanwhile, FGF2 and FGFR-1 complexes can enter into the nucleus, where they engage with a variety of sequence-specific transcription factors and further regulate the release and activity of matrix metalloproteinase 2 (MMP-2) and matrix metalloproteinase 9 (MMP-9), as well as the expression of proteins involved in the epithelial-mesenchymal transition [11,12].

Among the FGF-HS-FGFR complex, the basic amino acid residues of FGF2-FGFR2 form a positively charged cluster, which can attract negatively-charged HS chains for incorporation. Exogenous sulfated carbohydrates like heparin and its mimetic derivatives have long been studied for their competition with HS chains, to break the formation of the FGF2-HS-FGFR1 ternary complex and physiologically disrupt the function of cancer cells [13]. Several heparin mimics have been proven to be effective in blocking the formation of the FGF2-HS-FGFR1 ternary complex in vitro; however, their potential use might be limited by their potency, pharmacokinetic defect, and safety profile. Therefore, it would be an effective strategy to explore FGF2 inhibitors from existing drugs to facilitate cancer treatment.

Propylene glycol alginate sodium sulfate (PSS) is a heparin-like drug that was approved by the China Food and Drug Administration (CFDA) over 30 years ago to treat hyperlipidemia and ischemic cardio-cerebrovascular diseases [14]. PSS is obtained from alginate polysaccharide of Laminaria with multiple chemical modifications. PSS is composed of mannuronic acid (M) and guluronic acid (G) disaccharide repeat units and sulfates occurring at the C-2 or C-3 position of the sugar moiety, with a substitution at the C-6 position by propylene glycol. PSS has the following structural characteristics: an $\mathrm{M} / \mathrm{G}$ ratio above 1.5 , a molecular weight of $15-20 \mathrm{kDa}$, and an organic sulfur content of $9-14 \%$ [15].

Based on our previous research, it is well known that PSS and its fractions exert effects on anti-coagulation-related activities and anti-selectin activities [15-17]. Wu et al. reported that PSS and its oligosaccharides could significantly stimulate FGF2-induced cell proliferation in FGFR1c-expressing BaF3 murine pro-B cell line [18], suggesting that the potential binding effect occurs between PSS and FGF2. However, no studies have investigated the effects of PSS on FGF2-mediated functional regulation on a highly metastatic B16-F10 melanoma model and the related tumor microenvironment. As PSS possesses similar structural and bioactive properties to heparin, we hypothesized that PSS might exhibit an inhibitory effect on FGF2-mediated cellular proliferation, invasion, migration, or angiogenesis, as well as related downstream signaling.

\section{Results}

\subsection{Fibroblast Growth Factor 2 Bound to Propylene Glycol Alginate Sodium Sulfate with High Affinity}

PSS was investigated by surface plasmon resonance (SPR) analysis for its affinity with FGF2 and vascular endothelial growth factor 165 (VEGF165). As shown in Figure 1, PSS bound directly to FGF2, and the equilibrium dissociation constant $(\mathrm{KD})$ was $2.73 \times 10^{-8} \mathrm{M}$, which is comparable to heparin $\left(2.76 \times 10^{-8} \mathrm{M}\right)$. In contrast, weak affinity was detected between PSS and VEGF165 (Supplementary Table S1), while the KD of heparin was $8.09 \times 10^{-7} \mathrm{M}$. As FGF2 is a crucial growth factor to regulate angiogenesis and the function of tumor cells, these data indicate that FGF2 was probably a potential target for PSS to improve tumor environment. 

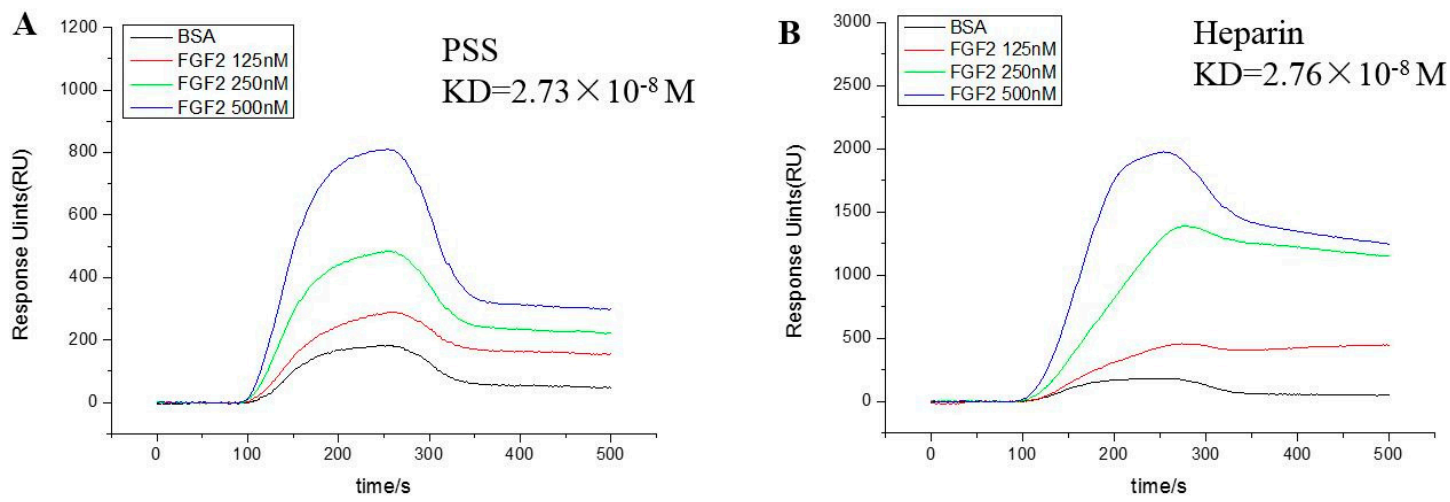

Figure 1. Analysis of the affinity between propylene glycol alginate sodium sulfate (PSS) and fibroblast growth factor 2 (FGF2). (A,B) were binding response curves of PSS and heparin with FGF2, respectively. PSS or Heparin (1-5 mM) was immobilized on Graft-to-PCL sensor chips. The mobile phase was FGF2 solution (dissolved in phosphate buffer solution (PBS)), and the concentrations were 125, 250, and $500 \mathrm{nM}$. The data obtained were analyzed and fitted by a PLEXERA SPR Data Analysis Module (DAM) to obtain the equilibrium dissociation constant (KD). Images are representative of three independent experiments with similar results.

2.2. Propylene Glycol Alginate Sodium Sulfate Inhibited the Fibroblast Growth Factor 2-Induced Invasion of B16-F10 Cells

FGF2 has been reported to play an important role in tumor metastasis; thus, we next wanted to evaluate the role of PSS in inhibiting tumor cell invasion and metastasis. PSS significantly inhibited the serum-induced invasion of B16-F10 in a dose-dependent manner. The Matrigel barrier approach was used to evaluate tumor cell metastasis. As shown in Figure 2A,B, after treating the cells for $16 \mathrm{~h}$, PSS inhibited invasion by $33.8 \%, 45.7 \%$, and $61.8 \%$ at concentrations of 25,50 , and $100 \mu \mathrm{g} / \mathrm{mL}$, respectively, in a dose-dependent manner. We further detected the anti-invasive effect of PSS on FGF2-mediated invasion. As shown in Figure 2C,D, 10\% FBS and $200 \mathrm{ng} / \mathrm{mL}$ FGF2 induced a comparable number of B16-F10 cells to penetrate the growth factor-reduced Matrigel, and PSS significantly inhibited FGF2-induced invasion by $59.1 \%$ at a concentration of $50 \mu \mathrm{g} / \mathrm{mL}$ after treating the cells for $8 \mathrm{~h}$.

\subsection{Propylene Glycol Alginate Sodium Sulfate Had No Effect on Cell Viability}

To ensure that the inhibitory effect of PSS on invasion was not due to the direct killing of tumor cells by PSS, we detected the proliferation ability of tumor cells after treatment with PSS for $48 \mathrm{~h}$. No inhibition on proliferation was observed, even when the concentration was more than $1000 \mu \mathrm{g} / \mathrm{mL}$ (Figure 3), suggesting that the inhibitory effect of PSS on invasion was not due to a reduction in the viability of cancer cells, but was likely due to the inhibition of tumor cell migration or the suppression of matrix-degrading enzymes. 


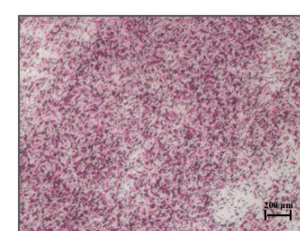

Untreated Control

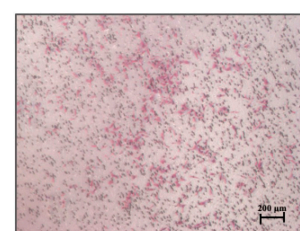

PSS $50 \mu \mathrm{g} / \mathrm{mL}$

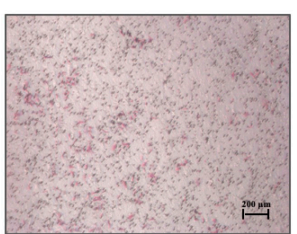

PSS $25 \mu \mathrm{g} / \mathrm{mL}$

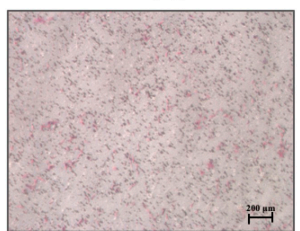

PSS $100 \mu \mathrm{g} / \mathrm{mL}$

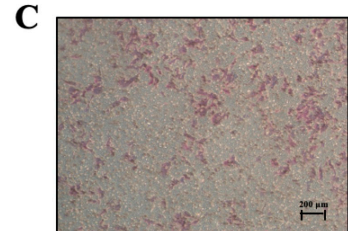

Negative control

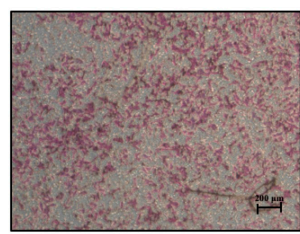

Control (with FGF2)

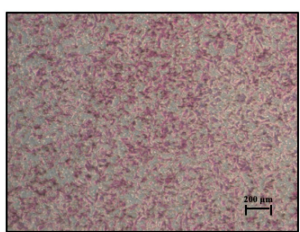

Control (with FBS)

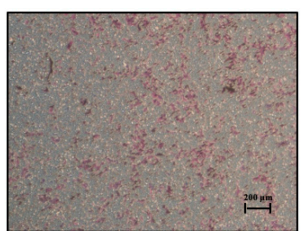

FGF2 + PSS $50 \mu \mathrm{g} / \mathrm{mL}$

D

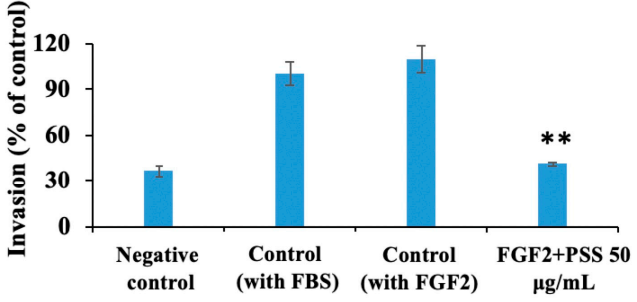

Figure 2. The effect of PSS on the invasion of B16-F10 cells. B16-F10 cells $\left(1.5 \times 10^{4}\right.$ cells/well) were seeded onto a membrane coated with Matrigel $(\mathbf{A}, \mathbf{B})$ or growth factor-reduced Matrigel $(\mathbf{C}, \mathbf{D})$, and were treated with various concentrations of PSS $(25,50,100 \mu \mathrm{g} / \mathrm{mL}$ ) for $16 \mathrm{~h}$ or $8 \mathrm{~h}$ (FGF2-mediated invasion of B16-F10). Cells that penetrated through to the lower surface of the membrane were stained with crystal violet and photographed under a light microscope at $40 \times$ magnification. Then, crystal violet was dissolved in $10 \%$ acetic acid, and the absorbance of the resulting solution was measured at 600 nm using a microplate reader (SpetraMAX i3, Molecular Devices, Sunnyvale, CA, USA). The controls included a negative control, complete medium only; control (with 10\% FBS) complete medium with 10\% FBS; control (with FGF2) complete medium with $200 \mathrm{ng} / \mathrm{mL}$ FGF2; and FGF2 + PSS $50 \mu \mathrm{g} / \mathrm{mL}$ complete medium with $200 \mathrm{ng} / \mathrm{mL}$ FGF2 and $50 \mu \mathrm{g} / \mathrm{mL}$ PSS. The results are from three independent experiments. ${ }^{* *} p<0.01$, significant difference between PSS-treated groups and the untreated control by Student's $t$-test.

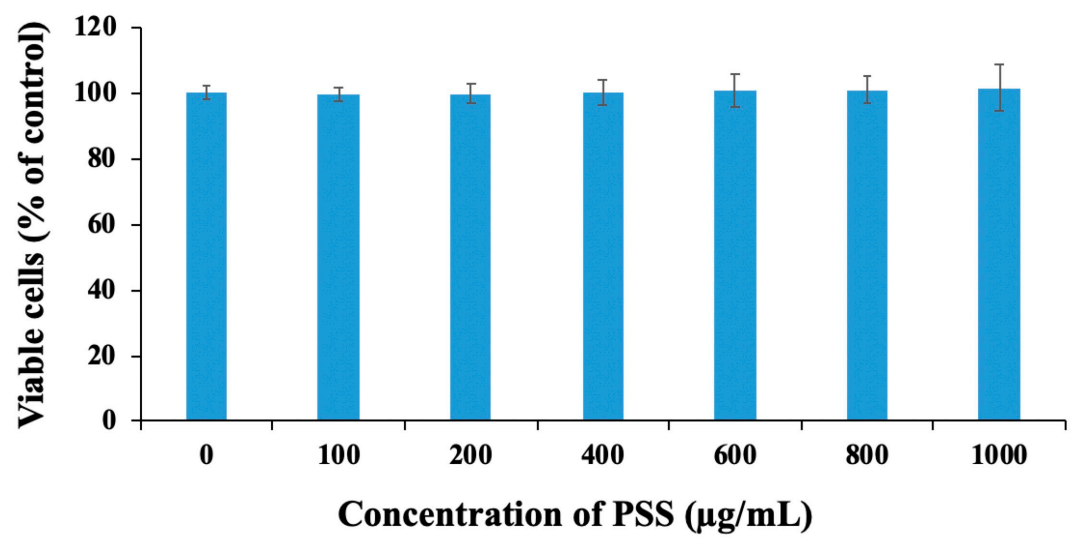

Figure 3. The effect of PSS on cell viability. B16-F10 cells $\left(0.5 \times 10^{4}\right.$ cells/well $)$ were seeded in 96 -well plates and incubated for $24 \mathrm{~h}$ to allow adherence. Various concentrations of PSS were added to the plates, and then the cells were further incubated for another $48 \mathrm{~h}$. The resazurin assay $(1 \mathrm{mg} / \mathrm{mL})$ was used for detection. The absorbance of each well was measured at $405 \mathrm{~nm}$ by a microplate reader (SpetraMAX i3, Molecular Devices, Sunnyvale, CA, USA). The data obtained are from three independent experiments. 


\subsection{Propylene Glycol Alginate Sodium Sulfate Had No Effect on the Migration of B16-F10 Cells}

Based on the results above, we further detected the effect of PSS on the migration of B16-F10 cells. As shown in Figure 4A,B, no obvious difference in the number of the migratory cells was found between the untreated control and the treatment with PSS at $400 \mu \mathrm{g} / \mathrm{mL}$. Meanwhile, the results of the scratch wound migration assays also revealed no significant difference across the wounded region after treatment with PSS at $400 \mu \mathrm{g} / \mathrm{mL}$ for $24 \mathrm{~h}$ (Figure 4C). PSS also had no effect on the migration of human umbilical vein endothelial (HUVEC) cells (Supplementary Figure S1).

$\mathbf{A}$

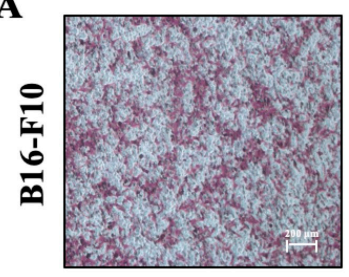

Untreated control

$\mathbf{C}$

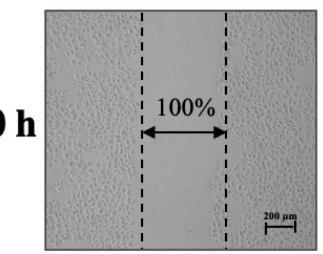

$24 \mathrm{~h}$

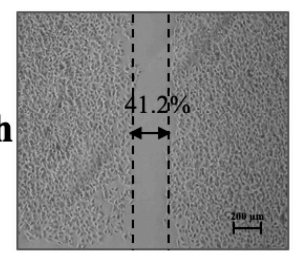

Untreated control

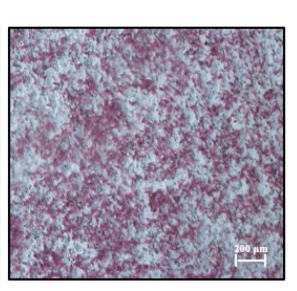

PSS $400 \mu \mathrm{g} / \mathrm{mL}$
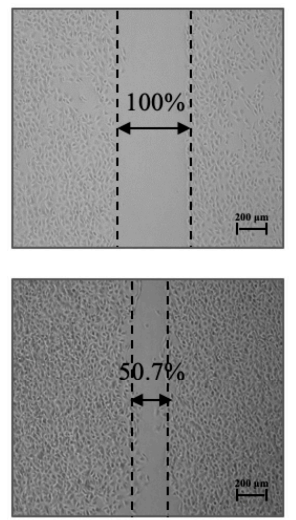

Heparin $400 \mu \mathrm{g} / \mathrm{mL}$
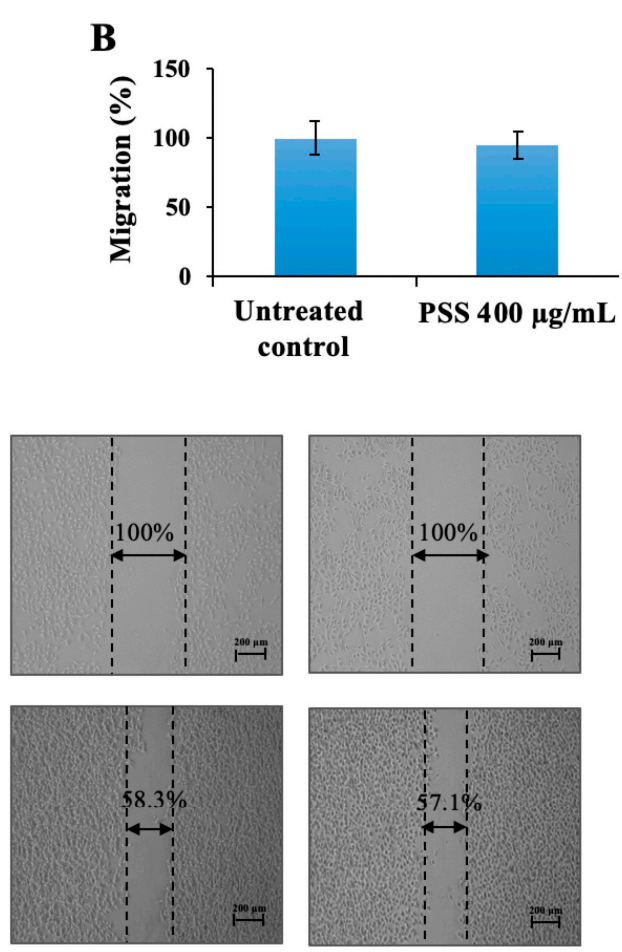

PSS $400 \mu \mathrm{g} / \mathrm{mL}$

Figure 4. The effect of PSS on the migration of B16-F10 cells. B16-F10 cells $\left(1 \times 10^{4}\right.$ cells/well $)$ were seeded into the upper chamber of Transwell plates, treated with various concentrations of PSS, and allowed to migrate for $16 \mathrm{~h}$. Cells that penetrated through to the lower surface of the membrane were stained with crystal violet and photographed under a light microscope at $40 \times$ magnification (A). Then, crystal violet was dissolved in $10 \%$ acetic acid, and the absorbance of the resulting solution was measured at $600 \mathrm{~nm}$ using a microplate reader (SpetraMAX i3, Molecular Devices, Sunnyvale, CA, USA) (B). For the wound healing assay (C), 70\% confluency B16-F10 cells in 12-well culture plates were scratched and then treated with FBS-free medium with PSS $(100,400 \mu \mathrm{g} / \mathrm{mL})$ or $400 \mu \mathrm{g} / \mathrm{mL}$ heparin. Three randomly selected views along the wound line in each well were photographed under an inverted microscope at $0 \mathrm{~h}$ and $24 \mathrm{~h}$ after incubation. The percentage of void area with respect to time 0 was determined using ImageJ software (ImageJ 1.8.0, Rawak Software Inc., Stuttgart, Germany). The results are from three independent experiments. ${ }^{* *} p<0.01$, significant difference between the PSS-treated groups and the untreated control by Student's $t$-test.

\subsection{Propylene Glycol Alginate Sodium Sulfate Down-Regulated the Expression of Activated Matrix} Metalloproteinase 2 and Matrix Metalloproteinase 9

The process of invasion involves the degradation of the ECM and the subsequent migration of tumor cells. Based on the data above, we confirmed that PSS inhibited the invasion of B16-F10 cells in a dose-dependent manner, but had no effect on tumor cell migration. Therefore, we examined whether PSS affected the expression or activity of crucial ECM-degrading enzymes. MMP-2 and MMP-9 are capable of degrading type IV collagen, which is the most abundant component of the basement 
membrane. Degradation of the basement membrane is an essential step for the metastatic progression of most cancers. Matrigel is an analog of the basement membrane. PSS inhibits the degradation of Matrigel by B16-F10. Therefore, it is necessary to detect whether PSS inhibits the expression and activity of MMP-2 and MMP-9. We first detected the effect of PSS on the expression of MMP-2 and MMP-9. After treating B16-F10 cells for $24 \mathrm{~h}$, PSS was found to decrease the expression of activated MMP-2 in a dose-dependent manner. PSS inhibited the level of MMP-2 by $1 \%, 15 \%, 35 \%$, and $67 \%$ compared to the untreated control at concentrations of $12.5,25,50$, and $100 \mu \mathrm{g} / \mathrm{mL}$ (Figure 5A,B), respectively. PSS also exerted an inhibitory effect on the expression of MMP-9. As shown in Figure 5C,D, PSS at a concentration of $100 \mu \mathrm{g} / \mathrm{mL}$ suppressed the expression of MMP-9 by $32 \%$.

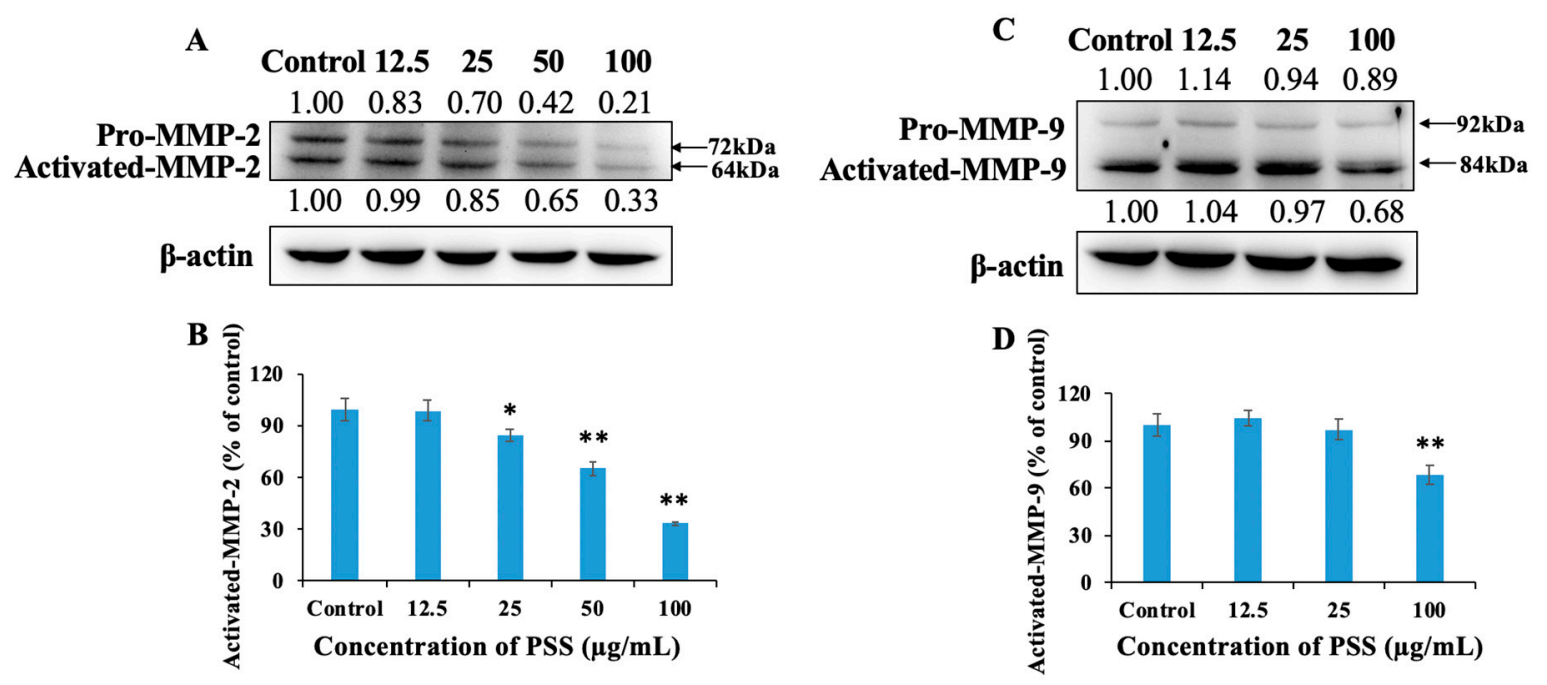

Figure 5. PSS down-regulated the level of activated matrix metalloproteinase 2 (MMP-2) and matrix metalloproteinase 9 (MMP-9) proteins in B16-F10 cells. Cells $\left(2 \times 10^{6}\right.$ cells/dish) were treated with PSS $(12.5,25,50,100 \mu \mathrm{g} / \mathrm{mL})$ for $24 \mathrm{~h}$. Then the cells were harvested, total protein was determined, and SDS-PAGE was performed, as described in the Materials and Methods section. The levels of activated MMP-2 (A,B) and MMP-9 (C,D) were estimated by Western blotting, also as described in the Materials and Methods section. The numbers underneath the blots represent the band intensities (normalized to the loading controls, means of three independent experiments) measured by ImageJ software (ImageJ 1.8.0, Rawak Software Inc., Stuttgart, Germany). The standard deviations were all within $\pm 15 \%$ of the means (data not shown); $\beta$-actin was used as an equal loading control. The experiments were repeated three times.

2.6. Propylene Glycol Alginate Sodium Sulfate Decreased the Activity of Matrix Metalloproteinase 2 and Matrix Metalloproteinase 9

We further detected the activity of MMP-2 and MMP-9 in B16-F10 cells after treatment with PSS for $24 \mathrm{~h}$. As shown in Figure 6B,C, PSS inhibited the activity of MMP-2 in a dose-dependent manner. At $25 \mu \mathrm{g} / \mathrm{mL}$, PSS slightly inhibited MMP-2, while at 50 and $100 \mu \mathrm{g} / \mathrm{mL}$, it suppressed the activity by $21.8 \%$ and $28.7 \%$, respectively. PSS also suppressed the activity of MMP-9 in a similar manner. The inhibition of PSS was $2.7 \%, 17.2 \%$, and $25.1 \%$ at concentrations of 25,50 , and $100 \mu \mathrm{g} / \mathrm{mL}$, respectively (Figure 6E,F). 
A

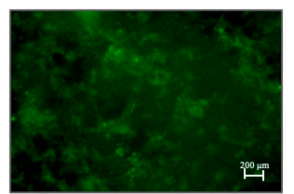

Untreated control

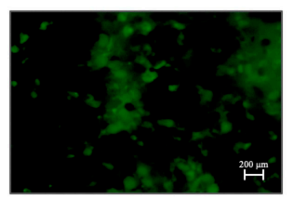

PSS $50 \mu \mathrm{g} / \mathrm{mL}$

D

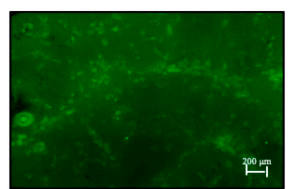

Untreated control

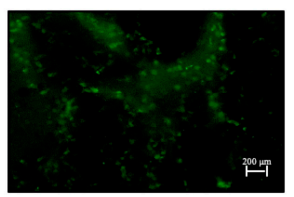

PSS $50 \mu \mathrm{g} / \mathrm{mL}$

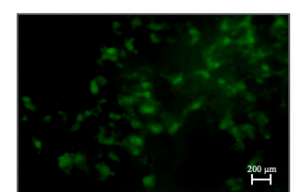

PSS $25 \mu \mathrm{g} / \mathrm{mL}$

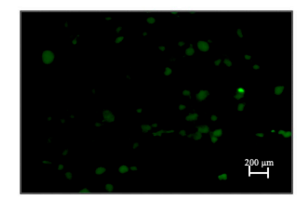

PSS $100 \mu \mathrm{g} / \mathrm{mL}$

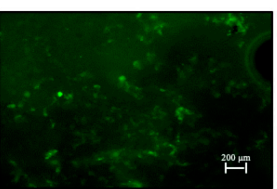

PSS $25 \mu \mathrm{g} / \mathrm{mL}$

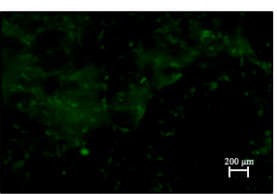

PSS $100 \mu \mathrm{g} / \mathrm{mL}$

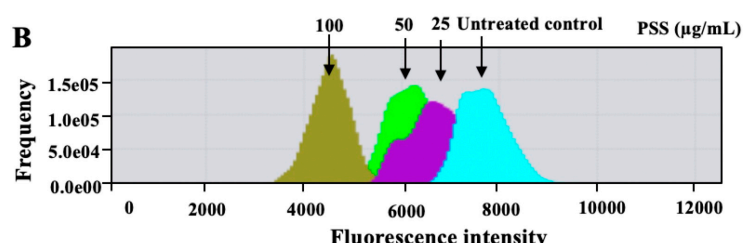

C

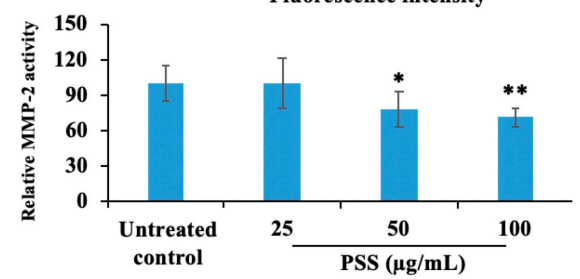

E

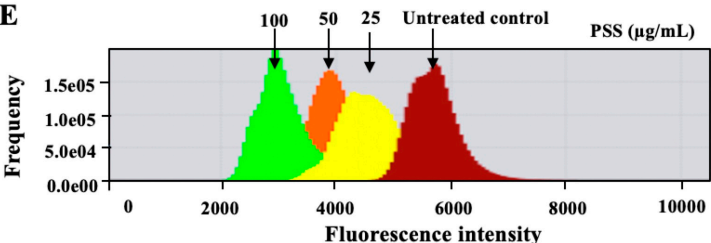

F

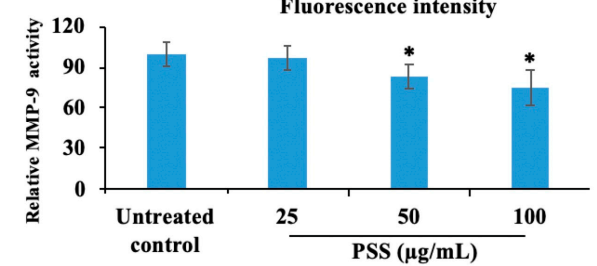

Figure 6. The effect of PSS on the activity of MMP-2 and MMP-9 in B16-F10 cells. The activity of MMP-2 (A-C) and MMP-9 (D-F) was tested using the GENMED Kit (Genmed Scientifics Inc., Wilmington, DE, USA). Cells $\left(1 \times 10^{5}\right.$ cells/well) were seeded in 12 -well culture plates with a glass slide to reach $50 \%$ confluence. After being washed with PBS, fresh serum-free culture medium was added to the plate in the presence or absence of serial treatments of PSS $(25,50,100 \mu \mathrm{g} / \mathrm{mL})$ for $24 \mathrm{~h}$. The GENMED kit was used to detect the fluorescence intensity. The green dots represent the catalytic sites for MMP-2 or MMP-9, and the fluorescence intensity represents the amount of the degraded gelatin. Fluorescence was visualized in 10 randomly selected fields of view for each cell slide under a fluorescence microscope (Colibri 7, ZEISS, Jena, Germany), and the fluorescence intensity was quantified by ZEN 2.3 lite software (ZEISS, Jena, Germany). The data shown above are from three independent experiments. ${ }^{*} p<0.05$, ** $p<0.01$, significant difference between the PSS-treated groups and the untreated control by Student's $t$-test.

\subsection{Propylene Glycol Alginate Sodium Sulfate Down-Regulated the Protein Expression of Vimentin}

Carcinoma cells make use of the epithelial-mesenchymal transition (EMT) as they become invasive. Indeed, the transition typically features the loss of cell-cell adherence proteins like cadherin, followed by the loss of apico-basal polarity, and finally, gaining the ability to migrate and invade. To investigate the potential role of PSS in the EMT, two crucial EMT markers in B16-F10 cells were examined by western blot. The expression of Vimentin was decreased by $41 \%$ and $47 \%$ in the presence of PSS at concentrations of 50 and $100 \mu \mathrm{g} / \mathrm{mL}$, respectively (Figure 7), while a slight increase was detected in the level of E-cadherin. Additionally, other proteins involved in the regulation of invasion and migration did not show any change in expression after treatment with PSS. 
A
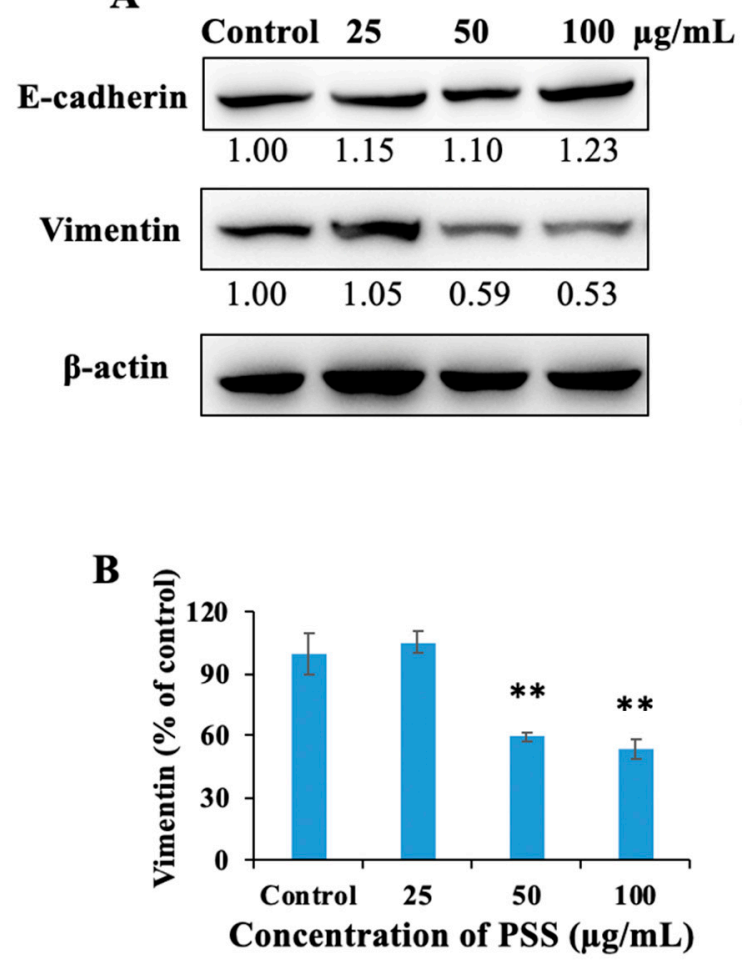

$\mathbf{C}$

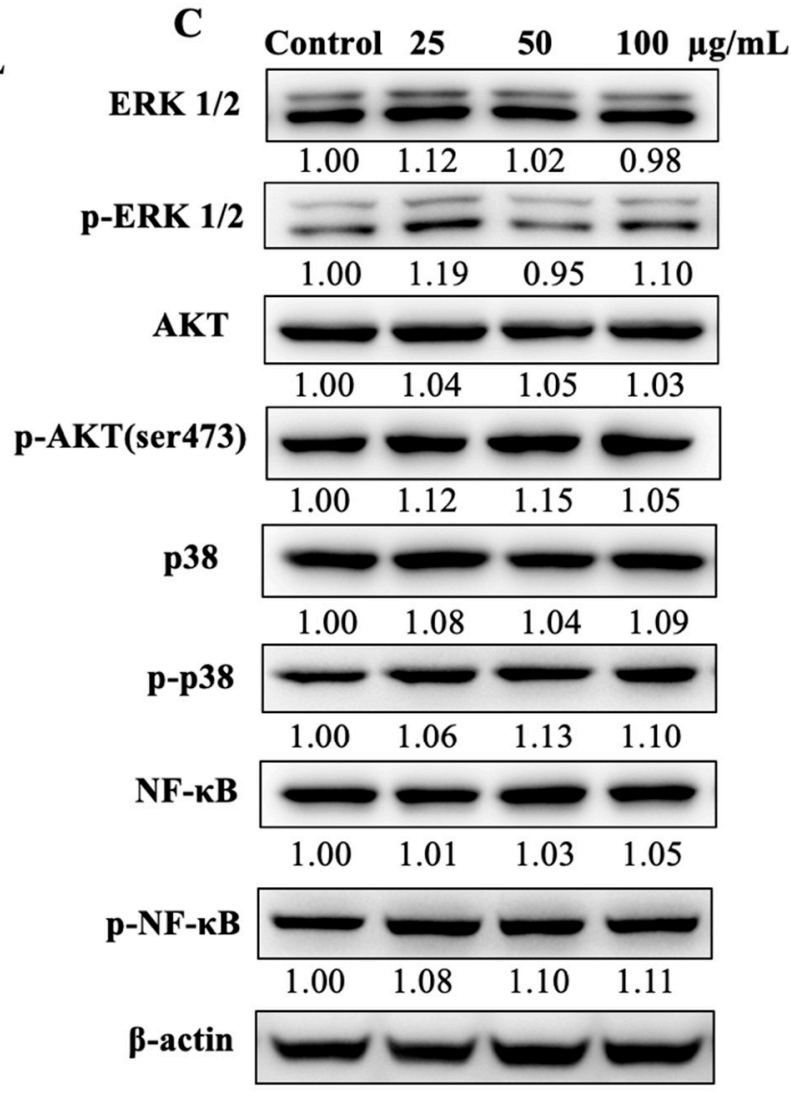

Figure 7. PSS down-regulated the protein expression of Vimentin in B16-F10 cells. Cells $\left(2 \times 10^{6}\right.$ cells/dish) were treated with PSS $(25,50,100 \mu \mathrm{g} / \mathrm{mL})$ for $24 \mathrm{~h}$. The cells were harvested, total protein was determined, and SDS-PAGE was performed as described in the Materials and Methods section. The levels of ERK 1/2, p-ERK 1/2, AKT, p-AKT, p38, p-p38, NF-kB, p-NF-kB, Vimentin, and E-cadherin were estimated by Western blotting, as described in the Materials and Methods section. $(\mathbf{A}, \mathbf{B})$ The protein expression level of Vimentin and E-cadherin in B16-F10 cells. (C) The levels of other proteins mentioned above in B16-F10 cells. The numbers underneath the blots represent the band intensities (normalized to the loading controls, means of three independent experiments) measured by ImageJ software (ImageJ 1.8.0, Rawak Software Inc., Stuttgart, Germany). The standard deviations were all within $\pm 15 \%$ of the means (data not shown); $\beta$-actin was used as an equal loading control. The experiments were repeated three times.

\subsection{Propylene Glycol Alginate Sodium Sulfate Inhibited Angiogenesis}

We next assessed the capacity of PSS to inhibit angiogenic activity using rat aortic rings and chick chorioallantoic membrane models. As shown in Figure 8A,B, PSS inhibited the outgrowth of new microvessels in a dose-dependent manner. The molecular weight of sulfated polysaccharides including PSS played crucial roles to determine their bioactivities. To illuminate the interaction between molecular weight and anti-angiogenesis potency of PSS, we further detected the effects of PSS fractions with various molecular weights (Mw) (H1: Mw $21.91 \mathrm{kDa}$; H3: Mw 13.68 kDa; H5: Mw $6.56 \mathrm{kDa}$; H7: Mw $3.10 \mathrm{kDa}$; H8: Mw $2.26 \mathrm{kDa}$ ) [17] on new blood vessel formation, using the same model. The data showed that the inhibitory effect of the fractions closely correlated with the molecular weight. The $\mathrm{H} 1$ fraction $(\mathrm{Mw}=21.91 \mathrm{kDa})$ exhibited the most potent effect among all five fractions, and the inhibitory effect was reduced as the molecular weight decreased (Figure 8C,D). Meanwhile, in the chick chorioallantoic membrane model, PSS suppressed vessel formation at doses of 100 and $200 \mu \mathrm{g} / \mathrm{egg}$ (Figure 8E,F). 
A

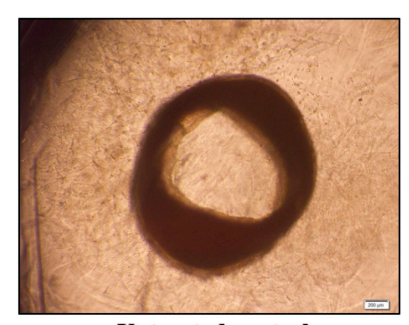

Untreated control

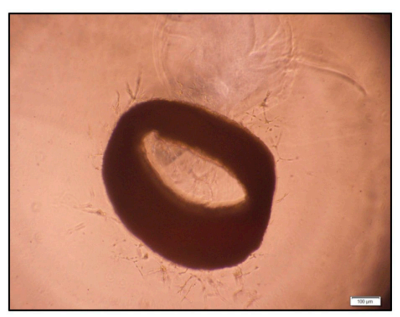

$100 \mu \mathrm{g} / \mathrm{mL}$

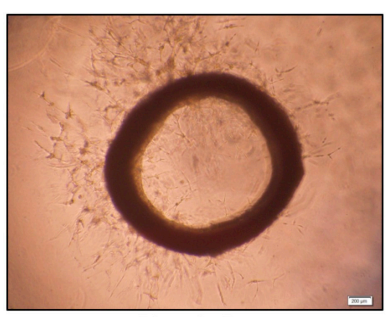

$50 \mu \mathrm{g} / \mathrm{mL}$

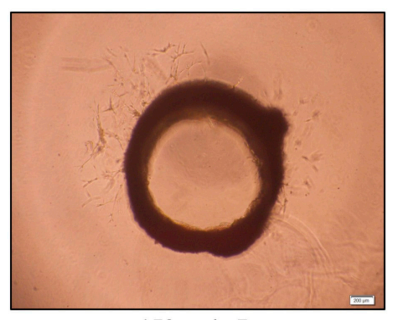

$150 \mu \mathrm{g} / \mathrm{mL}$
B

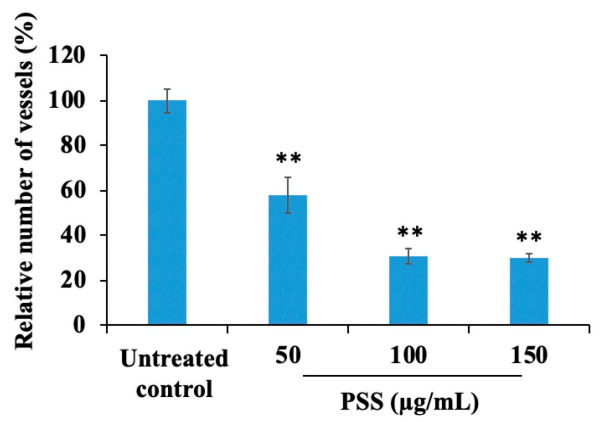

C
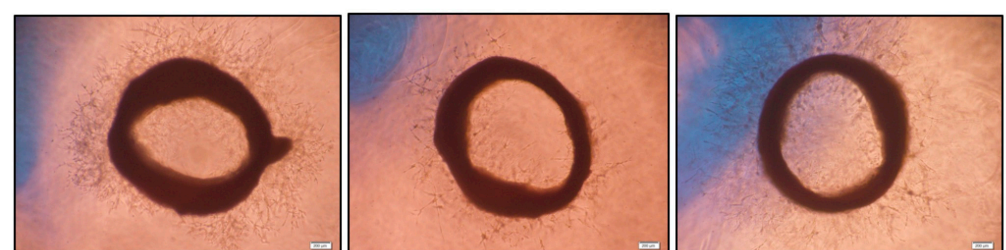

Untreated control

H1 $100 \mu \mathrm{g} / \mathrm{mL}$

H3 $100 \mu \mathrm{g} / \mathrm{mL}$

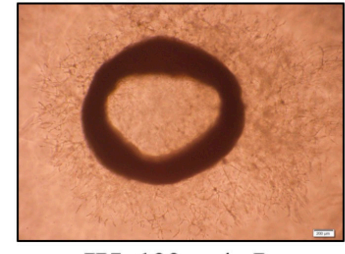

H5 $100 \mu \mathrm{g} / \mathrm{mL}$

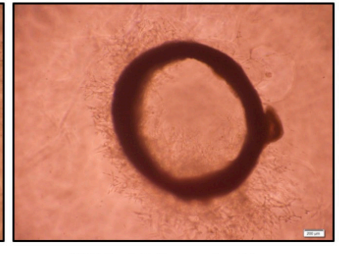

H7 $100 \mu \mathrm{g} / \mathrm{mL}$

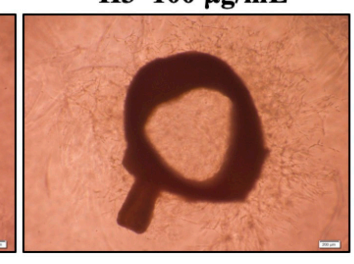

H8 $100 \mu \mathrm{g} / \mathrm{mL}$

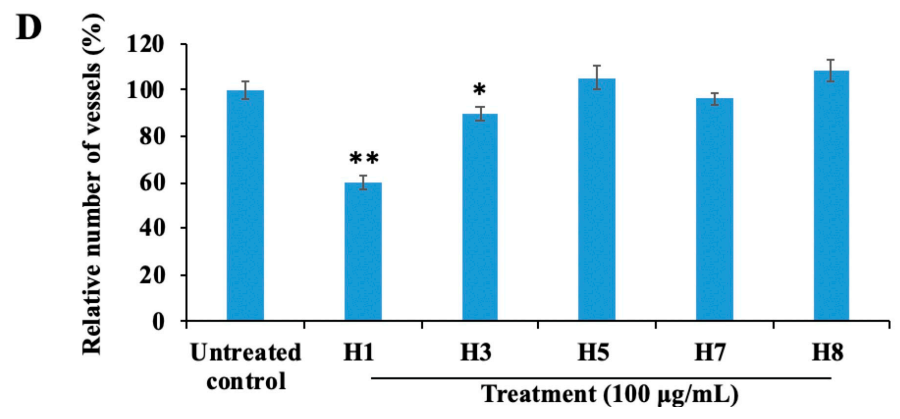

Figure 8. Cont. 
$\mathbf{E}$

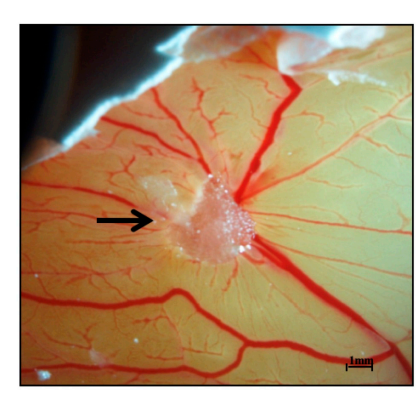

Untreated control

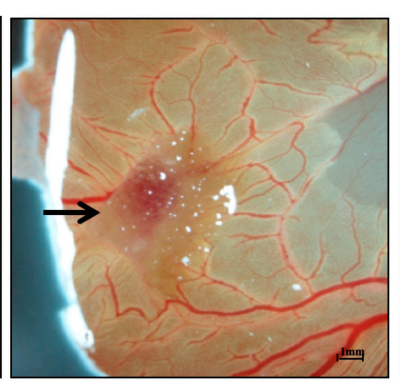

$100 \mu \mathrm{g} / \mathrm{egg}$

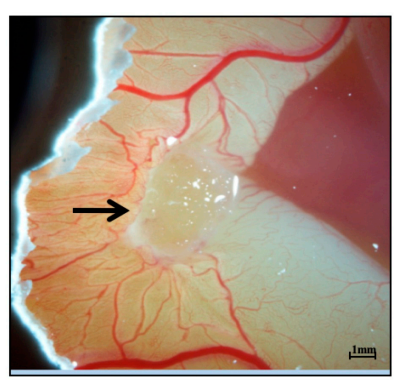

$200 \mu \mathrm{g} / \mathrm{egg}$

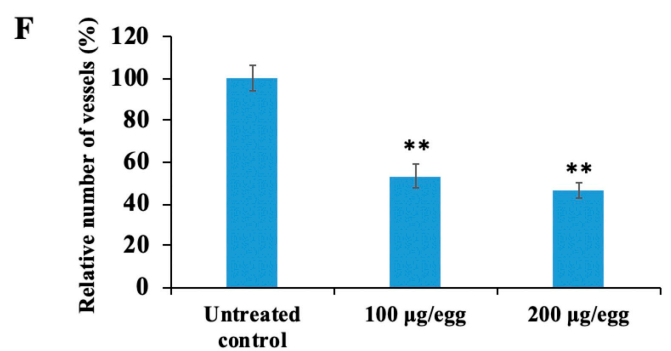

Figure 8. PSS suppresses angiogenesis. The inhibitory effect of PSS on microvessel outgrowth arising from rat aortic rings. Aortic rings were embedded in Matrigel in 96-well plates and then cultured with medium containing various concentrations of PSS (50, 100, $150 \mu \mathrm{g} / \mathrm{mL})$ for seven days (A,B). The effect of fractionated PSS on angiogenesis in the rat aortic ring model. The method used was the same as above (C,D). The effect of PSS on angiogenesis in the chick chorioallantoic membrane assay. Gelatin sponges $(5 \mathrm{~mm} \times 5 \mathrm{~mm})$ saturated with various concentrations of PSS solution or normal saline were inserted into seven-day-old fertilized eggs (E,F). After incubation for another $48 \mathrm{~h}$, the zones of neovascularization under and around the gelatin sponge were photographed under an anatomic microscope (Colibri 7, ZEISS, Jena, Germany) and the black arrows in the photos pointed at the site of gelatin sponge. The total vessel number was quantified by ImageJ software (ImageJ 1.8.0, Rawak Software Inc., Stuttgart, Germany). ${ }^{*} p<0.05,{ }^{* *} p<0.01$, significant difference between the PSS or PSS fraction-treated groups and the untreated control by the Student's $t$-test.

\subsection{Propylene Glycol Alginate Sodium Sulfate Inhibited Fibroblast Growth Factor 2-Mediated Angiogenesis}

To confirm the possible effect of PSS on FGF2-mediated angiogenesis, we cultured rat aortic rings in a serum-free medium, with $200 \mathrm{ng} / \mathrm{mL}$ FGF2 in the plate coating with growth factor-reduced Matrigel. As shown in Figure 9, little sprouting was observed in the negative control ring, while substantially more sprouting was observed in the FGF2-treated ring. PSS at $100 \mu \mathrm{g} / \mathrm{mL}$ decreased the level of sprouting to the amount in the negative control, and $200 \mu \mathrm{g} / \mathrm{mL}$ completely suppressed sprouting. 


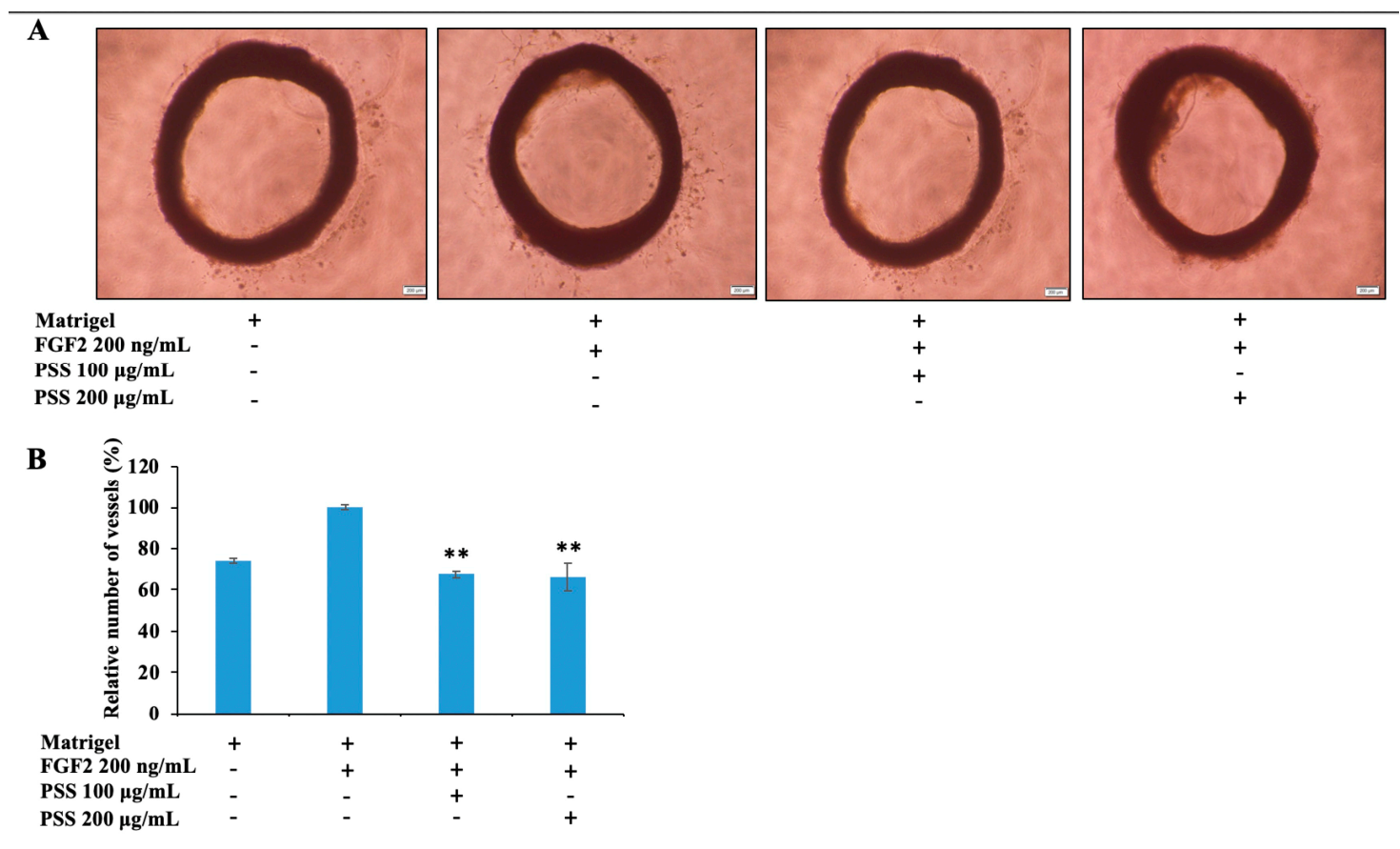

Figure 9. PSS suppresses FGF2-induced microvessel outgrowth in a rat aortic ring model. (A) Aortic rings were embedded in growth factor-reduced Matrigel in 96-well plates, and were then cultured with medium containing $200 \mathrm{ng} / \mathrm{mL}$ FGF2 and various concentrations of PSS (100, $200 \mu \mathrm{g} / \mathrm{mL})$ for seven days. Images are representative of three independent experiments with similar results. (B) The total vessel number was quantified by ImageJ software (ImageJ 1.8.0, Rawak Software Inc., Stuttgart, Germany). ** $p<0.01$, significant difference between the PSS-treated groups and the FGF2 control by Student's $t$-test.

\section{Discussion}

In this study, we observed that PSS has a major impact on invasion and angiogenesis in murine melanoma B16-F10 cells. FGF2 is a proangiogenic factor involved in tumor angiogenesis, invasion and migration. The present findings show that FGF2 bound to PSS with high affinity and inhibited FGF2-mediated angiogenesis in a rat aortic ring model. Moreover, PSS could suppress a FGF2-mediated invasion. The results of a further mechanism study indicate that PSS down-regulated the expression of activated MMP-2 and MMP-9, and also suppressed their activity. In addition, PSS was found to decrease the protein levels of Vimentin, which is known to participate in EMT. Notably, PSS did not elicit any changes in cancer cell viability, even though the concentration was more than $1000 \mu \mathrm{g} / \mathrm{mL}$.

Previous data indicated that the KD value for heparin binding to FGF2 ranges from 1 to $71 \mathrm{nM} \mathrm{[19-22].}$ These values were affected by a variety of factors, including the method used to determine them, the ionic strength of the buffer, the size and source of the heparin, and the source of the growth factor. In our system, we obtained similar KD values for FGF2 binding to PSS or heparin, indicating that PSS was comparable to heparin in terms of binding to FGF2. We further analyzed the electrostatic potential surface of FGF2. As shown in Supplementary Figure S2, FGF2 displayed a mass area of positive charge in the surface; hence, it could easily bind negative charged compounds. PSS and heparin possess similar sulfate group contents (32.39\% and 34\%, respectively) and similar KD values to FGF2; therefore, we presume that the sulfate of the two polysaccharides probably accounted for their affinity to FGF2.

FGF2 is known to interact with $\mathrm{N}$-sulfoglucosamine (GlcNS) and 2-O-sulfated iduronate residues (IdoUA (2S)) in heparin and HS [23,24], but the additional presence of 6-O-sulfation is required for biological activity $[25,26]$. PSS is a heparin-like drug, which is composed of repeating units of mannuronic acid $(\mathrm{M})$ and guluronic acid $(\mathrm{G})$, with $2-\mathrm{O}$ and $3-\mathrm{O}$ sulfate groups in the sugar rings. Groups that are 2-O-sulfated play a crucial role in mediating the binding of heparin with FGF2. Because PSS and heparin exhibited a comparable affinity to FGF2 and, we presume that 2-O-sulfated PSS might 
also be crucial for promoting the interaction of PSS with FGF2. To confirm this presumption, further research should be performed to elucidate the structure-activity relationship.

FGF2 and VEGF165 are the most important growth factors, and can be blocked by heparin to reduce angiogenesis. We also detected the affinity of PSS with VEGF165; however, PSS exhibited weaker affinity to VEGF165 $\left(\mathrm{KD}=1.78 \times 10^{-4} \mathrm{M}\right)$ than heparin $\left(\mathrm{KD}=8.09 \times 10^{-7} \mathrm{M}\right)$. Zhao et al. [27] reported that the specific structural features of heparin, such as the content of sulfate, sugar ring stereochemistry, and conformation, determined the affinity of heparin-derived oligosaccharides to VEGF165. Moreover, the positive charge on the surface of VEGF165 was distributed in a dispersed state (Supplementary Figure S2). Based on the above information, we presume that the conformation of PSS might not fit the stereochemical structure of VEGF165.

It was well-documented that the molecular weight of sulfated polysaccharides including PSS played crucial roles in determining their bioactivities. Our previous study showed that the average molecular weight of PSS was about $17 \mathrm{kDa}$ and the distribution range of molecular weight was about $2 \sim 20 \mathrm{kDa}$ [17]. Unlike the small molecular compounds, which generally bind to domains with catalytic activity of targeting proteins, sulfated polysaccharides possessed large amount of negative charge and generally interacted with proteins rich in positive potential on the surface of proteins. Theoretically, the longer sugar chains (the higher molecular weight) of the negative charged polysaccharide was endowed with the stronger binding affinity to target proteins and further exerted obvious bioactivities. Here, the higher molecular weight of PSS fractions exerted stronger inhibitory effect on angiogenesis which was consistent with the trend in previous publications $[17,28]$. Similarly, we speculated that it might be the same trends of PSS fractions in other experiments of the manuscript.

For the first time, we evaluated the effect of PSS on the highly metastatic B16-F10 melanoma cells and the related tumor environment. PSS itself has no inhibitory effect on the growth of B16-F10 cells-however, it suppressed FGF2-mediated angiogenesis and invasion of B16-F10 cells, and also decreased the level of Vimentin, which might help enhance the sensitivity of tumor cells to chemotherapy. Moreover, to fully elucidate the effects of PSS on the tumor microenvironment, further research should be conducted to investigate whether PSS exerts inhibitory effects on other cells involved in the tumor microenvironment, such as endothelial cells, fibroblasts, and immune cells. Meanwhile, further research should be done to combine PSS with chemotherapeutic drugs to check whether a synergistical effect happens.

\section{Materials and Methods}

\subsection{Cell Culture and Reagents}

The murine melanoma B16-F10 cell line was all obtained from the Type Culture Collection of the Chinese Academy of Sciences (Shanghai, China). The B16-F10 cells were cultured in RPMI-1640 supplemented with $10 \%(v / v)$ heat-inactivated FBS and $1 \%(v / v)$ penicillin-streptomycin. HUVECs were obtained from the Procells company (Shanghai, China) and cultured in Ham's F-12K supplemented with $100 \mu \mathrm{g} / \mathrm{mL}$ Heparin, $50 \mu \mathrm{g} / \mathrm{mL}$ ECGs, $10 \%(v / v)$ heat-inactivated FBS, and $1 \%(v / v)$ penicillin-streptomycin solution. Cells were cultured at $37{ }^{\circ} \mathrm{C}$ in a humidified atmosphere containing $5 \% \mathrm{CO}_{2}$. Cells were maintained at subconfluency, and the culture medium was changed every other day. The B16-F10 cells used were between 3 and 30 passages.

PSS was provided by Chia Tai Haier Pharmaceutical Co., Ltd. (Qingdao, China). Heparin (201 U/mg) was obtained from Wanbang Pharmaceuticals Company (Xuzhou, China). All proteins were purchased from Sino Biological (Beijing, China). All antibodies were purchased from Cell Signaling Technology (Cell Signaling Technology Inc., MA, USA). Matrigel was purchased from Corning Company (Tewksbury, MA, USA). All other chemicals and solvents were of analytical grade and purchased from Sinopharm Group Co. Ltd. (Beijing, China) 


\subsection{The Binding Kinetics of Propylene Glycol Alginate Sodium Sulfate and Fibroblast Growth Factor 2}

The kinetics and specificity of the binding between PSS derivatives and FGF2 and VEGF165 proteins were determined by a PlexArray ${ }^{\circledR}$ HT SPR system (Plexera Inc., Seattle, DC, USA). Briefly, PSS (1-5 mM) were immobilized on Graft-to-PCL sensor chips by UV crosslinking for $15 \mathrm{~min}$, according to an established protocol. The mobile phase was FGF2 or VEGF165 solution (dissolved in PBS), and the concentrations used were 125,250 , and $500 \mathrm{nM}$. The data obtained were analyzed and fitted by PLEXERA SPR DAM to obtain the equilibrium dissociation constant (KD).

\subsection{Cell Invasion}

Transwell chambers ( $6.5 \mathrm{~mm}$ diameter, $8 \mu \mathrm{m}$ pore size; Corning Life Sciences) were coated with $100 \mu \mathrm{L}$ of diluted Matrigel. Then, $0.6 \mathrm{~mL}$ of medium containing $10 \%$ FBS was added to the lower chambers, and cells suspended in serum-free medium at a density of $1.5 \times 10^{5}$ cells $/ \mathrm{mL}$ were seeded $(0.1 \mathrm{~mL})$ in the upper chambers. Various concentrations of PSS $(25,50,100 \mu \mathrm{g} / \mathrm{mL})$ were added to both of the upper and lower chambers. After incubation for $16 \mathrm{~h}$ or $8 \mathrm{~h}$ (FGF2-mediated invasion of B16-F10), cells were fixed with cold $4 \%$ paraformaldehyde and stained with $0.1 \%$ crystal violet, and the cells that had not migrated were removed from the upper chambers. The remaining cells were photographed in five random fields per membrane. The dye was dissolved in $80 \mu \mathrm{L}$ of acetic acid, and the absorbance of the resulting solution was measured at $600 \mathrm{~nm}$ using a microplate reader (SpetraMAX i3, Molecular Devices, Sunnyvale, CA, USA).

\subsection{Cell Proliferation Assay}

B16-F10 cells $\left(0.5 \times 10^{4}\right.$ cells/well) were seeded in 96-well culture plates in $100 \mu \mathrm{L}$ of culture medium and incubated for $24 \mathrm{~h}$. Subsequently, $100 \mu \mathrm{L}$ of complete medium without or with various concentrations of PSS $(100,200,400,600,800,1000 \mu \mathrm{g} / \mathrm{mL})$ were added. After incubation for $48 \mathrm{~h}$, $10 \mu \mathrm{L}$ of resazurin solution $(1 \mathrm{mg} / \mathrm{mL})$ was then added to each well, and the cells were incubated for another $4 \mathrm{~h}$. The fluorescence of each well was measured at $544 \mathrm{~nm}$ and $595 \mathrm{~nm}$ by a microplate reader (SpetraMAX i3, Molecular Devices, Sunnyvale, CA, USA).

\subsection{Cell Migration}

First, $0.6 \mathrm{~mL}$ medium containing 10\% FBS was added to the lower chamber of Transwell chambers (6.5 mm diameter, $8 \mu \mathrm{m}$ pore size; Corning Life Sciences), and cells suspended in a serum-free medium at a density of $1.5 \times 10^{5}$ cells $/ \mathrm{mL}$ were seeded $(0.1 \mathrm{~mL})$ in the upper chambers. Then, $400 \mu \mathrm{g} / \mathrm{mL}$ PSS was added to both the upper and lower chambers. After incubation for $16 \mathrm{~h}$, the cells were fixed by cold $4 \%$ paraformaldehyde, stained by $0.1 \%$ crystal violet, and cells that had not migrated were removed from the upper chambers. The remaining cells were photographed in five random fields per membrane. The dye was dissolved in $80 \mu \mathrm{L}$ of acetic acid, and the absorbance of the resulting solution was measured at $600 \mathrm{~nm}$ using a microplate reader (SpetraMAX i3, Molecular Devices, Sunnyvale, CA, USA).

\subsection{The Wound Healing Assay}

The effect of PSS on migration was analyzed in vitro using a wound healing assay. B16-F10 cells were seeded in 12-well culture plates to reach $70 \%$ confluency. The cell monolayer was scratched vertically down the center of each well with a sterile $200 \mu \mathrm{L}$ micropipette tip, and rinsed carefully with phosphate buffer solution (PBS) three times to remove cell debris. FBS-free medium with varying concentrations of PSS $(100,400 \mu \mathrm{g} / \mathrm{mL})$ or $400 \mu \mathrm{g} / \mathrm{mL}$ heparin was added to each well. Three randomly selected views along the wound line in each well were photographed under an inverted microscope at $0 \mathrm{~h}$ and $24 \mathrm{~h}$ after incubation. The percentage of void area with respect to time 0 was determined using ImageJ software (ImageJ 1.8.0, Rawak Software Inc., Stuttgart, Germany). 


\subsection{Western Blot Analysis}

B16-F10 cells $\left(2 \times 10^{6}\right.$ cells per well) were seeded into a $10 \mathrm{~cm}$ dish for $24 \mathrm{~h}$, and then cells were treated with different concentrations of PSS $(12.5,25,50,100 \mu \mathrm{g} / \mathrm{mL})$ for $24 \mathrm{~h}$. The medium was removed, and the cells were washed with PBS three times. Cells were then lysed in $200 \mu \mathrm{L}$ of lysis buffer on ice. The total protein was determined using the Bicinchoninic Acid (BCA) Kit (Solarbio, Beijing, China). Equal amounts of protein in the cell extracts were fractionated by $10 \%$ SDS-PAGE, and then electrotransferred onto polyvinylidene fluoride (PVDF) membranes. After blocking with TBST (20 mM Tris-buffered saline and 0.1\% Tween) containing 5\% nonfat dry milk for $1 \mathrm{~h}$ at room temperature, the membranes were incubated for $2 \mathrm{~h}$ with monoclonal antibodies, such as anti-MMP-9, anti-MMP-2, anti-E-cadherin, anti-Vimentin, anti-ERK 1/2, anti-p-ERK 1/2, anti-AKT, anti-p-AKT (Ser473), anti-p38, anti-p-p38, anti-p-p38, anti-NF- $\mathrm{B}$, anti-p-NF- $\mathrm{kB}$, and anti- $\beta$-actin, which were purchased from Cell Signaling Technology. The membranes were then washed three times and incubated with HRP-conjugated secondary antibodies (Abcam, Cambridge, Massachusetts, USA). The proteins were then detected using chemiluminescence agents (Amersham ECL, GE Healthcare, Buckinghamshire, UK).

\subsection{In Situ Zymography Localization of Matrix Metalloproteinase 2 and Matrix Metalloproteinase 2 Activity}

MMP-2/9 activity was tested on the slides of cells using the GENMED Kit (Genmed Scientifics Inc., Wilmington, DE, USA) according to the manufacturer's instructions (GENMED80062.4/80062.6, GENMED). B16-F10 were seeded in 12-well culture plates with a glass slide until they reached $50 \%$ confluence. After washing with PBS, fresh serum-free culture media was added to the plate in the presence or absence of serial PSS treatments, at concentrations ranging from $25-100 \mu \mathrm{g} / \mathrm{mL}$. After $24 \mathrm{~h}$, the glass slides were carefully removed. Reagent A was heated until melted. Then, $1000 \mu \mathrm{L}$ of reagent A was transferred into a $1.5 \mathrm{~mL}$ microtube and incubated for $10 \mathrm{~min}$ at $37^{\circ} \mathrm{C}$ in a thermostatic water bath. Reagent $\mathrm{B}$ was added to the $1.5 \mathrm{~mL}$ microtube and mixed well. The solution was added to the slide, a coverslip was added, and the slide was incubated in the dark at $4{ }^{\circ} \mathrm{C}$ for $10 \mathrm{~min}$ until the gel solidified. The prepared sections were then incubated at $37^{\circ} \mathrm{C}$ for $60 \mathrm{~min}$ in the dark. Fluorescence was visualized in 10 randomly selected fields of view for each cell slide at $40 \times$ magnification under a fluorescence microscope (Colibri 7, ZEISS, Jena, Germany). The fluorescence intensity of cells with active enzymes of MMP-2 or MMP-9 was quantified by the arithmetic mean intensity of ZEN 2.3 lite software. Each sample was assayed in triplicate, as described previously [29-31].

\subsection{Rat Aortic Ring Assay}

Aortas were obtained from six-week-old Sprague-Dawley rats. Each aorta was cut into 1-mm slices and washed in sterile PBS three times, and then imbedded into $55 \mu \mathrm{L}$ of Matrigel in 96-well plates. The aortic rings were then cultured in $100 \mu \mathrm{L}$ of DMEM medium with $10 \%$ FBS and various concentrations of PSS and PSS with different molecular markers. On day 7, the rings were photographed under a microscope (Colibri 7, ZEISS, Jena, Germany). The data obtained were analyzed and quantified using ImageJ software (ImageJ 1.8.0, Rawak Software Inc., Stuttgart, Germany). The animal experiments were approved by the Animal Ethics Committee of Marine Biomedical Research Institute of Qingdao (MBRI-2017-1106), and were strictly followed the guidelines of the institute.

\subsection{Chick Chorioallantoic Membrane Assay}

Fertilized eggs were incubated in a constant-temperature incubator maintained at $37^{\circ} \mathrm{C}$ and $40 \%-60 \%$ humidity for seven days. Gentle suction was applied to the hole located at the broad end of the egg to create a false air sac directly over the chick chorioallantoic membrane (CAM), and a $1-2 \mathrm{~cm}^{2}$ segment was immediately removed from the eggshell. A round gelatin sponge $(5 \mathrm{~mm} \times 5 \mathrm{~mm})$ saturated with PSS solution (100 or $200 \mu \mathrm{g} / \mathrm{egg}$ ) or saline was placed into the area between the pre-existing vessels, and the embryos were further incubated for $48 \mathrm{~h}$. The zones of neovascularization under and around the gelatin 
sponge were photographed under a stereomicroscope (SZX2-ILLT, OLYMPUS). The data obtained were analyzed and quantified using ImageJ software (ImageJ 1.8.0, Rawak Software Inc., Stuttgart, Germany).

\subsection{Statistical Analysis}

Statistical analysis for in vitro was performed using Excel. A two-tailed Student's unpaired $t$-test was performed to compare the untreated control group with the treated groups. The results were considered significant when $p<0.05\left({ }^{*}, p<0.05 ;{ }^{* *}, p<0.01\right)$. Independent experiments were conducted with a minimum of two biological replicates per condition to allow statistical comparison. Error bars represent the standard error of the mean, and the $p$ values are indicated. All experiments were repeated at least three times.

Supplementary Materials: The following are available online at http://www.mdpi.com/1660-3397/17/5/257/s1, Table S1: Analysis of the affinity between PSS and VEGF165, Figure S1: The effect of PSS on the migration of HUVEC cells, Figure S2: The electrostatic potential surface of FGF2 and VEGF165.

Author Contributions: H.M., P.Q., X.X., M.X., and H.X. performed the experiments. P.Q. designed the experiments. J.Y. and C. L. analyzed data. H.M. and P.Q. wrote the manuscript. J.Y., C.L., and Y.C. revised the manuscript. All the authors approved the final manuscript. All authors discussed the drafts and approved the final manuscript for publication.

Funding: This work was supported by The National Natural Science Fund (Grant No. 31701221), The Marine S\&T Fund of Shandong Province for Pilot National Laboratory for Marine Science and Technology (Qingdao) (No.2018SDKJ0404-4), and the Shandong Science and Technology Project (Grant No. 2014GGH215001). Qingdao Leading Talents Program (Grant No. 16-8-3-11-zhc), "Ao Shan Talents" Program Supported by Qingdao National Laboratory for Marine Science and Technology (Grant No. 2017ASTCP-OS11).

Conflicts of Interest: The authors declare that they have no competing financial interests to disclose.

\section{Abbreviations}

$\begin{array}{ll}\text { PSS } & \text { propylene glycol alginate sodium sulfate } \\ \text { CAM } & \begin{array}{l}\text { chick chorioallantoic membrane } \\ \text { epithelial-mesenchymal transition }\end{array} \\ \text { EMT } & \text { dissociation constant } \\ \text { KD } & \text { fibroblast growth factor } \\ \text { FGF } & \text { fibroblast growth factor 2 } \\ \text { FGF2 } & \text { fibroblast growth factor receptors } \\ \text { FGFRs } & \text { matrix metalloproteinase 2 } \\ \text { MMP-2 } & \text { matrix metalloproteinase 9 } \\ \text { MMP-9 } & \text { surface plasmon resonance } \\ \text { SPR } & \text { heparan sulfate } \\ \text { HS } & \text { heparan sulfate proglycan } \\ \text { HSPG } & \text { mannuronic acid } \\ \text { M } & \text { guluronic acid } \\ \text { G } & \text { human umbilical vein endothelial cells } \\ \text { HUVECs } & \end{array}$

\section{References}

1. De Aguiar, R.B.; Parise, C.B.; Souza, C.R.; Braggion, C.; Quintilio, W.; Moro, A.M.; Navarro Marques, F.L.; Buchpiguel, C.A.; Chammas, R.; de Moraes, J.Z. Blocking FGF2 with a new specific monoclonal antibody impairs angiogenesis and experimental metastatic melanoma, suggesting a potential role in adjuvant settings. Cancer Lett. 2016, 371, 151-160. [CrossRef] [PubMed]

2. Rodeck, U.; Melber, K.; Kath, R.; Menssen, H.D.; Varello, M.; Atkinson, B.; Herlyn, M. Constitutive expression of multiple growth factor genes by melanoma cells but not normal melanocytes. J. Investig. Dermatol. 1991, 97, 20-26. [CrossRef] [PubMed]

3. Rusnati, M.; Presta, M. Fibroblast growth factors/fibroblast growth factor receptors as targets for the development of anti-angiogenesis strategies. Curr. Pharm. Des. 2007, 13, 2025-2044. [CrossRef] 
4. Bikfalvi, A.; Klein, S.; Pintucci, G.; Rifkin, D.B. Biological roles of fibroblast growth factor-2. Endocr. Rev. 1997, 18, 26-45. [PubMed]

5. Compagni, A.; Wilgenbus, P.; Impagnatiello, M.A.; Cotten, M.; Christofori, G. Fibroblast growth factors are required for efficient tumor angiogenesis. Cancer Res. 2000, 60, 7163-7169. [PubMed]

6. Itoh, N.; Ornitz, D.M. Evolution of the Fgf and Fgfr gene families. Trends Genet. 2004, 20, 563-569. [CrossRef] [PubMed]

7. Ibrahimi, O.A.; Zhang, F.; Hrstka, S.C.; Mohammadi, M.; Linhardt, R.J. Kinetic model for FGF, FGFR, and proteoglycan signal transduction complex assembly. Biochemistry 2004, 43, 4724-4730. [CrossRef]

8. Brown, A.; Robinson, C.J.; Gallagher, J.T.; Blundell, T.L. Cooperative heparin-mediated oligomerization of fibroblast growth factor-1 (FGF1) precedes recruitment of FGFR2 to ternary complexes. Biophys. J. 2013, 104, 1720-1730. [CrossRef] [PubMed]

9. Jaye, M.; Schlessinger, J.; Dionne, C.A. Fibroblast growth factor receptor tyrosine kinases: Molecular analysis and signal transduction. Biochim. Biophys. Acta 1992, 1135, 185-199. [CrossRef]

10. Sterner, E.; Masuko, S.; Li, G.; Li, L.; Green, D.E.; Otto, N.J.; Xu, Y.; DeAngelis, P.L.; Liu, J.; Dordick, J.S.; et al. Fibroblast growth factor-based signaling through synthetic heparan sulfate blocks copolymers studied using high cell density three-dimensional cell printing. J. Biol. Chem. 2014, 289, 9754-9765. [CrossRef] [PubMed]

11. Strutz, F.; Zeisberg, M.; Ziyadeh, F.N.; Yang, C.Q.; Kalluri, R.; Muller, G.A.; Neilson, E.G. Role of basic fibroblast growth factor-2 in epithelial-mesenchymal transformation. Kidney Int. 2002, 61, 1714-1728. [CrossRef]

12. Liu, J.F.; Crepin, M.; Liu, J.M.; Barritault, D.; Ledoux, D. FGF-2 and TPA induce matrix metalloproteinase-9 secretion in MCF-7 cells through PKC activation of the Ras/ERK pathway. Biochem. Biophys. Res. Commun. 2002, 293, 1174-1182. [CrossRef]

13. Chung, S.W.; Bae, S.M.; Lee, M.; Al-Hilal, T.A.; Lee, C.K.; Kim, J.K.; Kim, I.S.; Kim, S.Y.; Byun, Y. LHT7, a chemically modified heparin, inhibits multiple stages of angiogenesis by blocking VEGF, FGF2 and PDGF-B signaling pathways. Biomaterials. 2015, 37, 271-278. [CrossRef] [PubMed]

14. Zeng, Y.; Yang, D.; Qiu, P.; Han, Z.; Zeng, P.; He, Y.; Guo, Z.; Xu, L.; Cui, Y.; Zhou, Z.; et al. Efficacy of Heparinoid PSS in Treating Cardiovascular Diseases and Beyond-A Review of 27 Years Clinical Experiences in China. Clin. Appl. Thromb. Hemost. 2016, 22, 222-229. [CrossRef]

15. Xue, Y.T.; Ren, L.; Li, S.; Wang, L.L.; He, X.X.; Zhao, X.; Yu, G.L.; Guan, H.S.; Li, C.X. Study on quality control of sulfated polysaccharide drug, propylene glycol alginate sodium sulfate (PSS). Carbohydr. Polym. 2016, 144, 330-337. [CrossRef] [PubMed]

16. Xin, M.; Ren, L.; Sun, Y.; Li, H.H.; Guan, H.S.; He, X.X.; Li, C.X. Anticoagulant and antithrombotic activities of low-molecular-weight propylene glycol alginate sodium sulfate (PSS). Eur. J. Med. Chem. 2016, 114, $33-40$. [CrossRef] [PubMed]

17. Ma, H.; Qiu, P.; Xin, M.; Xu, X.; Wang, Z.; Xu, H.; Yu, R.; Xu, X.; Zhao, C.; Wang, X.; et al. Structure-activity relationship of propylene glycol alginate sodium sulfate derivatives for blockade of selectins binding to tumor cells. Carbohydr. Polym. 2019, 210, 225-233. [CrossRef]

18. Wu, J.; Zhang, M.; Zhang, Y.; Zeng, Y.; Zhang, L.; Zhao, X. Anticoagulant and FGF/FGFR signal activating activities of the heparinoid propylene glycol alginate sodium sulfate and its oligosaccharides. Carbohydr. Polym. 2016, 136, 641-648. [CrossRef]

19. Li, L.Y.; Seddon, A.P. Fluorospectrometric analysis of heparin interaction with fibroblast growth factors. Growth Factors 1994, 11, 1-7. [CrossRef] [PubMed]

20. Kamei, K.; Wu, X.; Xu, X.; Minami, K.; Huy, N.T.; Takano, R.; Kato, H.; Hara, S. The analysis of heparin-protein interactions using evanescent wave biosensor with regioselectively desulfated heparins as the ligands. Anal. Biochem. 2001, 295, 203-213. [CrossRef]

21. Lee, M.K.; Lander, A.D. Analysis of affinity and structural selectivity in the binding of proteins to glycosaminoglycans: Development of a sensitive electrophoretic approach. Proc. Natl. Acad. Sci. USA 1991, 88, 2768-2772. [CrossRef] [PubMed]

22. Cochran, S.; Li, C.; Fairweather, J.K.; Kett, W.C.; Coombe, D.R.; Ferro, V. Probing the interactions of phosphosulfomannans with angiogenic growth factors by surface plasmon resonance. J. Med. Chem. 2003, 46, 4601-4608. [CrossRef]

23. Faham, S.; Hileman, R.E.; Fromm, J.R.; Linhardt, R.J.; Rees, D.C. Heparin structure and interactions with basic fibroblast growth factor. Science 1996, 271, 1116-1120. [CrossRef] [PubMed] 
24. Turnbull, J.E.; Fernig, D.G.; Ke, Y.; Wilkinson, M.C.; Gallagher, J.T. Identification of the basic fibroblast growth factor binding sequence in fibroblast heparan sulfate. J. Biol. Chem. 1992, 267, 10337-10341.

25. Guimond, S.; Maccarana, M.; Olwin, B.B.; Lindahl, U.; Rapraeger, A.C. Activating and inhibitory heparin sequences for FGF-2 (basic FGF). Distinct requirements for FGF-1, FGF-2, and FGF-4. J. Biol. Chem. 1993, 268, 23906-23914.

26. Pye, D.A.; Vives, R.R.; Turnbull, J.E.; Hyde, P.; Gallagher, J.T. Heparan sulfate oligosaccharides require 6-O-sulfation for promotion of basic fibroblast growth factor mitogenic activity. J. Biol. Chem. 1998, 273, 22936-22942. [CrossRef]

27. Zhao, W.; McCallum, S.A.; Xiao, Z.; Zhang, F.; Linhardt, R.J. Binding affinities of vascular endothelial growth factor (VEGF) for heparin-derived oligosaccharides. Biosci. Rep. 2012, 32, 71-81. [CrossRef]

28. Stevenson, J.L.; Choi, S.H.; Varki, A. Differential metastasis inhibition by clinically relevant levels of heparins-correlation with selectin inhibition, not antithrombotic activity. Clin. Cancer Res. 2005, 11, 7003-7011. [CrossRef]

29. Duan, Y.; Zhao, X.; Ren, W.; Wang, X.; Yu, K.F.; Li, D.; Zhang, X.; Zhang, Q. Antitumor activity of dichloroacetate on C6 glioma cell: In vitro and in vivo evaluation. Onco. Targets Ther. 2013, 6, 189-198.

30. Xin, H.; Liang, W.; Mang, J.; Lin, L.; Guo, N.; Zhang, F.; Xu, Z. Relationship of gelatinases-tight junction proteins and blood-brain barrier permeability in the early stage of cerebral ischemia and reperfusion. Neural Regen. Res. 2012, 7, 2405-2412. [PubMed]

31. Wang, Z.; Chen, Z.; Yang, J.; Yang, Z.; Yin, J.; Duan, X.; Shen, H.; Li, H.; Wang, Z.; Chen, G. Treatment of secondary brain injury by perturbing postsynaptic density protein-95-NMDA receptor interaction after intracerebral hemorrhage in rats. J. Cereb. Blood Flow Metab. 2018. [CrossRef] [PubMed]

(C) 2019 by the authors. Licensee MDPI, Basel, Switzerland. This article is an open access article distributed under the terms and conditions of the Creative Commons Attribution (CC BY) license (http://creativecommons.org/licenses/by/4.0/). 